\title{
-LIG.A-Fabricated Compact mm-Wave Linear Accelerator Cavities
}

\section{J.j. Song, S. Bajikar. F. Decarlo. Y.W. Kang, R.L. Kustom. D.C. Mancini. A. Nassiri, and B. Lai.}

A.D. Feinerman, $U$. of Illinois at Chicago, Microfabrication Laboratory. Chicago, IL 60607
$\vee$. White, L. of Wisconsin at Madison, Center for X-ray Lithography. Madison. WI 53706

\section{Abstract}

Millimeter-wave it cavities for use in linear accelerators, fiee-electron lasers. and mm-wave undulators are under development at Argonne National Laboratory. Typical cavity dimensions are in the 1000 $\mathrm{mm}$ range. and the overall length of the accelerator structure, which consists of $30-100$ cavities, is about 50-100 $\mathrm{mm}$. An accuracy of $0.2 \%$ in the cavity dimensions is necessary in order to achieve a high $Q$ factor of the cavity. To achieve this, these structures are being fabricated using deep $X$-ray lithography, electroforming, and assembly (LIGA). The first prototype cavity structures are designed for $108 \mathrm{GHz}$ and $2 \mathrm{p} / 3$-mode operation. Input and output couplers are integrated with the cavity structures. The cavities are fabricated on copper substrates by electroforming copper into 1-mm-thick PMMA resists patterned by deep $x$-ray lithography and polishing the copper down to the desired thickness. These are fabricated separately and subsequently assembled with precision spacing and alignment using microspheres, optical fibers, or microfabricated spacers/alignment pieces. Details of the fabrication process, alignment, and assembly work are presented in here.

\section{INTRODUCTION}

All new concepts for proposed accelerators such as next-generation linear colliders or muon colliders require substantial advances in the area of $\pi+$ technology. For example, to maintain a reasonable over-all length at high center-of-mass energy. the main linac of an electron-positron linear collider must operate at high accelerating field gradient. Scaling accelerating structures to significantly higher frequencies could provide higher field gradient as proposed by P.B. Wilson [1].

The new micromachining technology, known as LIG.A. consists of deep-etched $x$-ray lithography (DXRL). electroplating. and micro-molding. The microtabrication processes have been devioped by $W$. Ehrteld and co-workers to the degree that submillimeter actuators. motors. and gears can be built with great accuracy and a high aspect ratio [2]. Electric tield levels as high as $50 \mathrm{MV} / \mathrm{m}$ and magnetic field levels of $1 \mathrm{~T}$ have been achieved with components. Specifically. this technology could orier significant advantages over conventional manufacturing methods in such areas as precision iabrication and massproduction.

The idea of applying these techniques to develop if cavities for $\mathrm{mm}$-wave linacs [3], undulators [4], freeelectron lasers [5]. and mm-wave amplitiers started at Argonne National Laboratory in 1993. A meter-long structure with similar accuracy that also provides channels for vacuum pumping, adequate cooling, and focusing elements for beam dynamics can be built. Major challenges of the DXRL techniques are: fabrication of the wafers into three-dimensional if structures, alignment and overiaw accuracy of the structures, adhesion of the poly-metryterthacrylate (PMMA) on the copper substrate, and selediofto developer to obtain high resolution. Efforthye been hrot toward meeting these challenges.

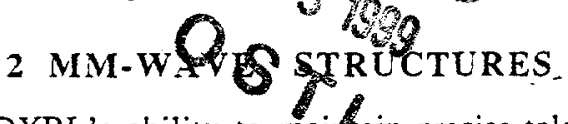

Due to DXRL's ability to mainain precise tolerances, it is ideally suited for the manufacture of rf components operating at frequencies between $30 \mathrm{GHz}$ and $300 \mathrm{GHz}$. The first two structures fabricated were a 32-cell, 108$\mathrm{GHz}$ constant-impedance cavity and a $66-\mathrm{cell}, 94-\mathrm{GHz}$ constant-gradient cavity. A 32-cell, 108-GHz constantimpedance cavity is a planar accelerating structure; its linac application has been investigated thoroughly, and its parameters are shown in Table 1 . In changing from a typical cylindrical symmetrical disk-like structure to a planar accelerating structure, there is not much loss in shunt impedance and Q-value (less than 5\%). An accelerating gradient of $100 \mathrm{MV} / \mathrm{m}$ is chosen for a practical $50-\mathrm{MeV}$ micro-linac application, but the accelerating gradient is not limited to that when the if system is operational in the pulse mode with less repetition-rate.

Table 1: The if Parameters of a 32-Cell. 108-GHz Constant-Impedance Cavity.

\begin{tabular}{|c|c|c|}
\hline Frequency & $\mathrm{f}$ & $108 \mathrm{GHz}$ \\
\hline Shunt Impedance & $\mathrm{R}$ & $312 \mathrm{M} \Omega / \mathrm{m}$ \\
\hline Quality Factor & $\mathrm{Q}$ & 2160 \\
\hline Operating Mode & $\mathrm{TW}$ & $2 \pi / 3$ \\
\hline Group Velocity & $\mathrm{v}_{\mathrm{g}}$ & $0.043 \mathrm{C}$ \\
\hline Attenuation Factor & $\alpha$ & $13.5 \mathrm{~m}^{-1}$ \\
\hline Accelerating Gradient & $\mathrm{E}$ & $100 \mathrm{\textrm {V }} / \mathrm{m}$ \\
\hline Peak Power & $\mathrm{P}$ & $30 \mathrm{~kW}$ \\
\hline
\end{tabular}

For a constant-impedance planar structure, the double-periodic structures with confluence in the $\pi$ mode designs were considered. The $2 \pi / 3$-mode operation in these structures can give high shunt impedance, group velocity, and low sensitivity on dimensional ertors. More detailed descriptions. such as if simulation using the MAFIA computer code, and the thermal analysis related to this structure can be found in Refs. 6 and 7 .

The constant-impedance structure is simple and can be easily tabricated. but may not be the best for 


\section{DISCLAIMER}

This report was prepared as an account of work sponsored by an agency of the United States Government. Neither the United States Government nor any agency thereof, nor any of their employees, make any warranty, express or implied, or assumes any legal liability or responsibility for the accuracy, completeness, or usefulness of any information, apparatus, product, or process disclosed, or represents that its use would not infringe privately owned rights. Reference herein to any specific commercial product, process, or service by trade name, trademark, manufacturer, or otherwise does not necessarily constitute or imply its endorsement, recommendation, or favoring by the United States Government or any agency thereof. The views and opinions of authors expressed herein do not necessarily state or reflect those of the United States Government or any agency thereof. 


\section{DISCLAIMER}

Portions of this document may be illegible in electronic image products. Images are produced from the best available original document. 
accelerator applications, primarily due to the difficulty of heat removal in the microstructure. In a constantimpeciance structure. the concentration of heat at the structure input can limit the high-power $r t$ operation of the siructure. To increase the shunt impedance of the structure, the thickness of the irises between the cells must be small (say $<0.1 \lambda$ ). However, heating imposes a limit in this case; heating at the center of the irises limits the maximum input power. Successful heat removal and uniform heat loading throughout the structure are important for optimum performance of the $\mathrm{mm}$-wave accelerating structure.

The constant-gradient linear accelerating structure has been used in many present-day accelerators due to its higher energy gain and better frequency characteristic. The constant-gradient structure has a higher shunt impedance and more uniform power dissipation. and is less sensitive to frequency deviations and beam break-up when compared to the constantimpedance structure. The control of cell-to-cell coupling in the side-coupled structures can be made to realize the constant-gradient planar structures.

The one limiting factor in the micromachining process is that the planar structure has to have uniform indentations on a planar wafer. Using microfabrication technology, it is more difficult to realize a constantgradient structure than a constant-impedance structure. Changing the group velocity along the structure while keeping the gap and cell depth dimensions constant is difficult. Since the structure needs to be manufactured on a planar wafer, adjusting the cell width and length with a constant depth within the structure is necessary. A constant-gradient structure can be realized with a cut in the iris between the adjacent cavity cells along the beam axis in each half structure. Figure 1 shows the constant-gradient structure with cuts in the irises, and its if parameters are summarized in Table $?$.

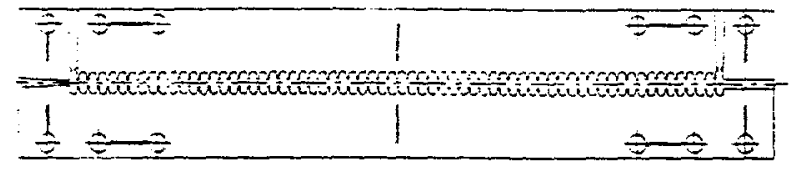

Figure 1: The 66-cell, 94-GHz constant-gradient cavity.

Table 2: 94-GHz linac/rf Parameters

\begin{tabular}{lll}
\hline Parameter & Symbol & Value \\
\hline Beam Energy & $E_{j}$ & $50 \mathrm{MeV}$ \\
Avg. Beam Current & $I_{b}$ & $1 \mathrm{~mA}$ \\
Frequency & $\mathrm{i}$ & $94-\mathrm{GHz}$ \\
Field Gradient & $\mathrm{E}$ & $100 \mathrm{MV} / \mathrm{m}$ \\
Wode of Operation & $\mathrm{TW}$ & $2 \pi / 3$ \\
No. of Cavities & $\mathrm{N}$ & 66 \\
Structure Length & 1 & $7 \mathrm{~cm}$ \\
ti Power & $\mathrm{P}$ & $30 \mathrm{~kW}$ \\
\hline
\end{tabular}

\section{FABRICATION}

The simplitied version of the DKRL process is shown in Fig. 2. It consists of making an $x$-ray mask, prepar- ing a sample and y-ray exposure, developing, and electroplating the structure. In DXRL, the requirements imposed on the resist materials, resist coating process, and development are much different from the thin resist layers. No dissolution of unexposed positive resist is allowed during development. and good adhesion of the high-aspect ratio resist structure to the copper substrate is essential. In addition. the microstructures must have high mechanical stability and low internal stresses to prevent stress corrosion during exposure and development. Also, the resist material must be compatible with the electroplating process.

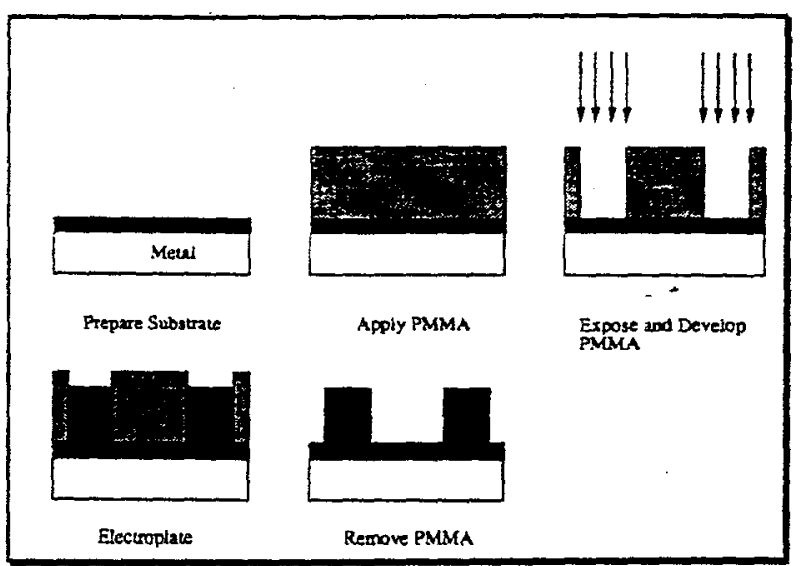

Figure 2: Simplified DXRL process.

DXRL with high-energy synchrotron radiation allows resists up to $1000 \mu \mathrm{m}$ thick to be fabricated with sub-micron accuracy. A high-accuracy DXRL mask was made by means of an intermediate mask--that is, in two steps. The first step was the photolithography. A plating base of Ti/Au $75 / 300 \AA$ was used for the ebeam writer and then 3-4m Au was plated on the intermediate mask. The second step used soft $x$-ray lithography at the Center for X-ray Lithography in Stoughton, Wisconsin (1-GeV Aladdin). For the DXRL mask, $45-\mu \mathrm{m}$ Au was plated over a $300-\mu \mathrm{m} \mathrm{Si}$ wafer where the $x$-ray was exposed and the resist removed. To observe the high depth-to-width aspect ratio in the final product, micron-range structures were patterned on the DXRL mask. To avoid alignment problems and $x$-ray diffraction, these two steps were done on the same sample substrate without a physical gap.

Poly-methylmethacrylate (PMMIA), up to $1 \mathrm{~mm}$ thick. was used as a positive resist. The copper substrate was diamond-finished to have a flatness of $1 \mathrm{\mu m}$ over $t$ inches. Then either an oxide film was grown to one micron thick or an equally thick $T i$ coating was deposited in order to promote better adhesion to the copper substrate. Through these processes, the flatness of the copper surtace is maintained. but is still rough enough to give good adhesion to the PMM.t sheet (a roughness of less than $0.1,4 \mathrm{~m}$ ! [8].

When the PMIMA film was casi onto the copper substrate. it was annealed at various temperatures 110 . $170^{\circ} \mathrm{C}$ for one to three hours 19 ]. The NSLS (National 


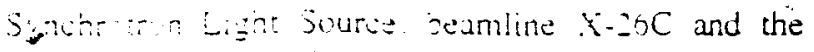
APS 2-3.V-A seamiline were used to expose the sample. The ransmitted $x-r a y$ intensity was calculated babed on the APS bending magnet parameters and is plotted in Fig. 3. The ratio of the top dose to the bottom tose for the $1-$ mm-thick PMMAt is about 1.1 . During the excosure. the sample was enclosed in a Hepurged housing with a Kapton window. and the sample holder basepiate was water cooled. The first Pt mirror with a grazing angle of $0.15^{\circ}$ was used to cut off all the high-energy $x$-rays above $10 \mathrm{keV}$ as shown in Figure 3. More intormation on the APS 2-B.I beamline for the DXRI can be found in Ret. 10.

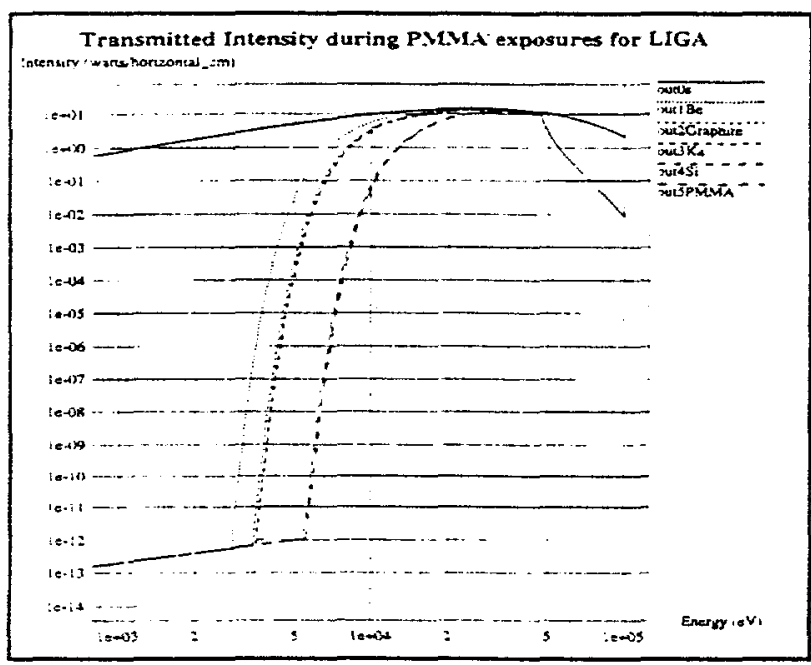

Figure 3: Transmitted $x$-ray intensity during PMMA exposures for DXRL at APS. energy vs. intensity.

Two different developers were used in the developing process. The first developer was a mixture of $60 \%$ vol 2-(2-butoxy-ethoxy) ethanol, 20\% terrahydro-1. 4 oxazine. 5\% 2-aminoethanol-1. and $15 \%$ DI water [11]. The allowed dose range was from $:$ to about 10 $\mathrm{kJ} / \mathrm{cm}^{3}$. Below the threshold the crosslinked resist could not be dissolved. and above this range damage to the resist can occur from production of gases in the PMMA. More characteristics of exposure and processing of thick PMMA can be found in Ref. 12. The second developer was methyl-iso-butyl ketone (MIBK) diluted with 2-propanol.

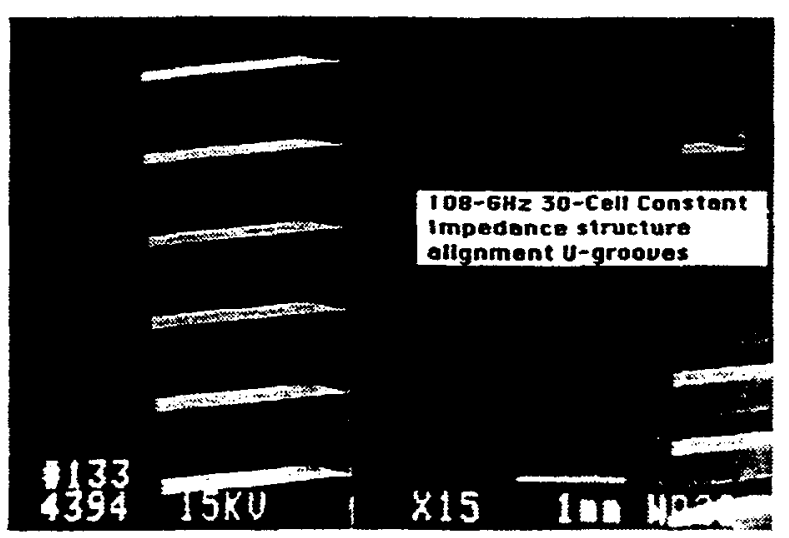

Figure 4: SEM picture of the $108-\mathrm{GHz}$ constantimpedance cavity structure.

After developing the microstructure, copper can be electroplated to the positive resist and the surface can be diamond-finished. The final electroplated structure for the prototype of the $108-\mathrm{GHz}$ constant-impedance cavity structure is shown in Figure.+

\section{SUMMARY AND FURTHER WORK}

- To get a size-controllable structure, details of both the developing process (e.g., use of ultrasonic cleaning) and the electro-plating process (pulse mode operation) have to be optimized.

- Two mirror-imaged fabricated structures for the 108$\mathrm{GHz}$ constant-impedance cavity have been aligned and are ready for network measurement.

- The metallurgical study of the copper-electroplated sample, recently done by $C$. Pearson at SLAC, shows that the level of oxygen in the sample appears to be too high. One has to improve the electroplating process for vacuum/high-power $\mathrm{rf}$.

- The bead-pull measurement setup for the LIGAfabricated $\mathrm{mm}$-wave cavity structures in underway.

\section{ACKNOWLEDGMENTS}

This work was supported by the U.S. Department of Energy, Office of Basic Energy Sciences, under Contract No W-31-109-ENG-38. We would like to thank B. Bonivert at SNL and A. Farvid at SLAC for the copper-electroplating work; S. Sutton and G. Shea for the beam time on the X26C beamline at NSLS; Many thanks to A. Rehmani, K. Kim, and B. Popek for their technical assistance.

\section{REFERENCES}

[1] P.B. Wilson, SLAC-PUB-7263, Oct. (1996).

[2] W. Ehrfeld and D. Muechmeyer, Nucl. Instr. and Methods in Physics Res.. A203, 523 (1991).

[3] Y.W. Kang, et. al.. Proc. of the 1993 Particle Accelerator Conference, p. 549 (1993).

[4] J.J. Song et al.. SPIE-Micromachining and Microfabrication'96, Austin Texas, V2888 (1996).

[5] A. Nassiri et al.. IEEE. International Electron Device Conference, Washington DC, 169 (1993).

[6] Y.W. Kang et al., Proc. of the 1995 Particle Accelerator Conference. p. 640 (1995).

[7] P. Matthews, and A. Khounsary. private communication.

[8] F.J. Pantenburg et al.. "Adhesion problems in deepetch X-rav lithography caused by tluorescence radiation from the plating base." Microelectronics Eng.. V23. p. 223 (1994).

[9] H. Guckel et al.. MEMIs 1991. Vara, Japan. January. 1991

[10] B. Lai et al. SPIE-Micromachining and Microtabrication'96. Austin Texas. V2888 (1996).

[11]E.W. Ehrfeld et al., J. Vac. Sci. Technol. B6 (1). 178 (1988)

[12] F. DeCarlo et al. in these proceedings. 